\title{
A quantitative analysis of the direct and indirect costs of nitrogen fixation: a model based on Azotobacter vinelandii
}

\author{
Keisuke Inomura ${ }^{1}$, Jason Bragg ${ }^{2}$ and Michael J Follows ${ }^{1}$ \\ ${ }^{1}$ Department of Earth, Atmospheric and Planetary Sciences, Massachusetts Institute of Technology, \\ Cambridge, MA, USA and ${ }^{2}$ Research School of Biology, Australian National University, Canberra, \\ ACT, Australia
}

\begin{abstract}
Nitrogen fixation is advantageous in microbial competition when bioavailable nitrogen is scarce, but has substantial costs for growth rate and growth efficiency. To quantify these costs, we have developed a model of a nitrogen-fixing bacterium that constrains mass, electron and energy flow at the scale of the individual. When tested and calibrated with laboratory data for the soil bacterium Azotobacter vinelandii, the model reveals that the direct energetic cost of nitrogen fixation is small relative to the cost of managing intracellular oxygen. It quantifies the costs and benefits of several potential oxygen protection mechanisms present in nature including enhanced respiration (respiratory protection) as well as the production of extracellular polymers as a barrier to $\mathrm{O}_{2}$ diffusion, and increasing cell size. The latter mechanisms lead to higher growth efficiencies relative to respiratory protection alone. This simple, yet mechanistic framework provides a quantitative model of nitrogen fixation, which can be applied in ecological simulations.
\end{abstract}

The ISME Journal (2017) 11, 166-175; doi:10.1038/ismej.2016.97; published online 14 October 2016

\section{Introduction}

All organisms need nitrogen for the synthesis of important molecules including nucleic acids and proteins. Nitrogen pervades the environment in the form of $\mathrm{N}_{2}$ gas, yet it is often a limiting resource on land and in aquatic environments. Nitrogen fixation provides some marine and terrestrial prokaryotes with an ecological advantage but is typically associated with low growth efficiencies and rates (Kuhla and Oelze, 1988a, b; LaRoche and Breitbarth, 2005; Berman-Frank et al., 2007; Goebel et al., 2007), placing significant constraints on the relative fitness of nitrogen fixers and their biogeography. Here we address the question of what underpins the low growth efficiency of nitrogen fixers and develop a quantitative analysis that forms the basis for trait-based ecological and biogeochemical models.

One contribution to the low growth rate/efficiency of nitrogen fixers is the direct cost of reducing dinitrogen. Nitrogen fixation is catalyzed by the nitrogenase enzyme, and uses 8 electrons and at least

Correspondence: K Inomura, Department of Earth, Atmospheric and Planetary Sciences, Massachusetts Institute of Technology, Room 54-1425, 77 Massachusetts Avenue, Cambridge, MA 02139, USA.

E-mail: kinomura@mit.edu

Received 30 March 2016; revised 1 June 2016; accepted 7 June 2016; published online 14 October 2016
16 molecules of ATP to reduce each $\mathrm{N}_{2}$ molecule to two molecules of $\mathrm{NH}_{3}$ (Sohm et al., 2011).

$$
\begin{aligned}
& \mathrm{N}_{2}+8 \mathrm{e}^{-}+8 \mathrm{H}^{+}+16 \mathrm{ATP}+16 \mathrm{H}_{2} \mathrm{O} \rightarrow 2 \mathrm{NH}_{3} \\
& \quad+\mathrm{H}_{2}+16 \mathrm{ADP}+16 \mathrm{P}_{\mathrm{i}}
\end{aligned}
$$

Although the energetic expense of breaking the dinitrogen triple bond is high, this direct cost may not necessarily be the greatest challenge faced by nitrogen-fixing cells. Nitrogenase consists of an $\mathrm{Fe}$-protein and a Mo-Fe-protein and other metal cofactors whose activity is decreased upon exposure to oxygen (Gallon, 1981). Thus, aerobic nitrogen fixers have developed numerous strategies to protect nitrogenase from oxygen, particularly in oxygenic phototrophs. For example, in Anabaena and Nostoc the nitrogen-fixing cells also become heterocysts, losing the ability to fix carbon and building a thick cell coating, which is less permeable to oxygen (Neilson et al., 1971; Wolk, 1996; Golden and Yoon, 2003) demanding an exchange of metabolites between cells, as do nitrogen fixers in symbiotic relationships with other species. Free-living, unicellular aerobic nitrogen fixers use other strategies, including the separation of oxygenic photosynthesis and nitrogen fixation between day and night (for example, Colón-López et al., 1997; Misra, 1999; Tucker et al., 2001; Berman-Frank et al., 2003; Saito et al., 2011; Großkopf and LaRoche, 2012). Heterotrophic, soil-dwelling nitrogen fixers, such as Azotobacter vinlandii, use elevated rates of 

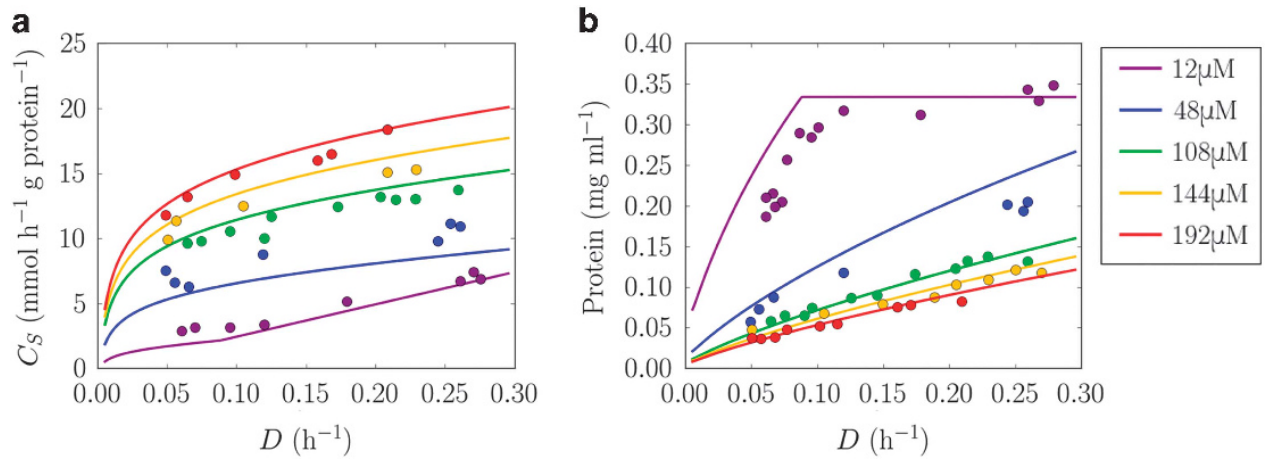

Figure 1 Continuous cultures of Azotobacter vinelandii with observed data (circles) redrawn from Kuhla and Oelze (1988b). Solid lines are the corresponding simulations from this work. (a) Protein-specific sucrose consumption rate, (b) standing stock of protein, all with respect to dilution (and growth) rate, $D$ ( $x$ axis) and oxygen concentration (colored points/lines). The legend indicates oxygen concentration.

respiration to deplete intracellular oxygen (Poole and Hill, 1997). They also produce an extracellular polymeric substance that impedes oxygen invasion (Sabra et al., 2000), and they maintain larger cell sizes (Post et al., 1982), which likely also reduces the specific oxygen-invasion rate.

Each of these strategies demands that the organism invests resources in nitrogen fixation that could otherwise be used for other activities, such as carbon fixation or biosynthesis, offsetting the ecological advantage of nitrogen fixation. The resulting reduction in growth rate and/or efficiency is the key to understanding the biogeography of nitrogen fixation in the environment (for example, Staal et al., 2003; Monteiro et al., 2010; Dutkiewicz et al., 2012). In current ecological and biogeochemical simulations, this cost is typically empirically imposed (for example, Krishnamurthy et al., 2007; Dutkiewicz et al., 2012; Stukel et al., 2014). Here we present a mechanistic and quantitative approach to modeling the cost of nitrogen fixation and its associated oxygen management. Although the model represents a generalized approach, we focus on the heterotrophic, nitrogen-fixing soil bacterium, A. vinelandii, for which extensive, quantitative laboratory characterizations have been published (for example, Post et al., 1982, 1983a, b; Kuhla and Oelze, 1988a, b; Allman et al., 1990; Poole and Hill, 1997; Oelze, 2000; Dixon and Kahn, 2004).

Laboratory cultures of Azotobacter (for example, Kuhla and Oelze, 1988a, b) have demonstrated a decrease in growth efficiency at all growth rates as the ambient concentration of oxygen in the medium was increased. This was manifested as an increased carbohydrate cost, which has been interpreted as enhanced energetically uncoupled respiration (exceeding the level required for biosynthesis; Nagai and Aiba, 1972; Kuhla and Oelze, 1988b) to manage intracellular oxygen concentration and maintain functional nitrogenase, hereafter termed 'respiratory protection' (Dalton and Postgate, 1969; Poole and Hill, 1997). This is illustrated in Figure 1a (data in circles; lines represent a model discussed later), in which the specific sucrose consumption rate increased with oxygen concentration. The sensitivity to oxygen manifests largely as a 'maintenance' effect, increasing overall carbohydrate consumption (Figure 1a) because the cell must be equally clear of oxygen even at very low growth and nitrogen fixation rates. Azotobacter encodes and expresses cytochrome bd, which has high oxygen consumption relative to ATP production (Poole and Hill, 1997). The reduction of growth efficiency with increasing oxygen concentration was also reflected in a lower standing stock of protein (Kuhl and Oelze, 1988b) in Figure 1b. At the lowest oxygen concentration $(12 \mu \mathrm{M})$ there was a sharp change in the slope at a dilution rate of $\sim 0.1$ per day.

However, it was noted that the increase in respiration is not linear with oxygen concentration, increasing less rapidly at concentrations above $70 \mu \mathrm{M}$ (Oelze, 2000) suggesting that other protection mechanisms must also be at play. $A$. vinelandii is also observed to increase in cell size in more oxygenated cultures (Post et al., 1982) and to form an external alginate capsule as a barrier to oxygen diffusion, which increases in molecular weight and gluronic acid content with higher oxygen conditions (Sabra et al., 2000).

The thorough characterization of the energetics of A. vinelandii in the laboratory (for example, Post et al., 1982; Bühler, et al., 1987a, b; Kuhla and Oelze, 1988a, b; Oelze 2000) provides an excellent opportunity to develop a quantitative, mechanistic model of nitrogen-fixer physiology, which we can employ both as a diagnostic tool and in dynamic ecological simulations. Shortly, we will present such a model, but first we consider the general principle that underpins it.

\section{Materials and methods}

In this section, we describe the core equations of the model. The entire equations are summarized in Supplementary Material S4 and the nomenclature is provided in Supplementary Material S5. 
Intracellular oxygen balance

Oxygen management is a key cost for nitrogen fixers that we seek to quantitatively model. First consider the rate of change of the intracellular oxygen, $Q_{\mathrm{O} 2}\left(\mathrm{~mol} \mathrm{O}_{2}\right.$ per cell) in a spherical microbe:

$\frac{\mathrm{d} Q_{\mathrm{O} 2}}{\mathrm{~d} t}=P_{\mathrm{O} 2}+4 \pi r \kappa_{\mathrm{O} 2}\left(\left[\mathrm{O}_{2}\right]-\left[\mathrm{O}_{2}\right]_{\mathrm{C}}\right)-\left(R_{\mathrm{S}}+R_{\mathrm{m}}+R_{\mathrm{P}}\right)$

Here, $\left[\mathrm{O}_{2}\right]$ and $\left[\mathrm{O}_{2}\right]_{\mathrm{C}}$ are the environmental and intracellular oxygen concentrations, respectively $\left(\mathrm{mol} \mathrm{O}_{2} \mathrm{~m}^{-3}\right)$. The first term on the right, $P_{\mathrm{O} 2}$ (mol $\mathrm{O}_{2}$ per cell per s) represents a source from oxygenic photosynthesis. The second term is a source because of transfer across the membranes of cell with the cytoplasmic radius $r$ (m per cell), governed by the oxygen gradient and the effective diffusivity across the membrane and external molecular boundary layer, $\kappa_{\mathrm{O} 2}\left(\mathrm{~m}^{2} \mathrm{~s}^{-1}\right)$. The third term, in parentheses, represents consumption of intracellular oxygen by respiration associated with synthesis $\left(R_{S}\right)$ including the direct cost of nitrogen fixation, maintenance $\left(R_{\mathrm{m}}\right)$ and respiratory protection $\left(R_{\mathrm{P}}\right)\left(\mathrm{mol} \mathrm{O}_{2}\right.$ per cell per s). $R_{\mathrm{S}}$ is related to the growth rate of the population, $\mu\left(\mathrm{s}^{-1}\right)$ by

$R_{\mathrm{S}}=\mu Q_{\mathrm{C}} Y_{\mathrm{S}}^{\mathrm{O} 2 \mathrm{BIO}}$

where $Q_{\mathrm{C}}$ is the carbon quota (mol C per cell) of the species in question and $Y_{\mathrm{S}}^{\mathrm{O} 2: \mathrm{BIO}}$ is the growth yield with respect to oxygen $\left(\mathrm{mol} \mathrm{O}_{2}\right.$ consumed per mol C biomass synthesized), which can be evaluated from the overall stoichiometry of the reactions (Heijnen and Roels, 1981; Rittmann and McCarty, 2001; see Supplementary Material S1).

As reducing intracellular oxygen concentration is critical for nitrogen fixers, consider the solution for the intracellular oxygen concentration $\left[\mathrm{O}_{2}\right]_{\mathrm{C}}$ at steady state $\left(\mathrm{d} Q_{\mathrm{O} 2} / \mathrm{d} t \approx 0\right)$ :

$\left[\mathrm{O}_{2}\right]_{\mathrm{C}}=\left[\mathrm{O}_{2}\right]+\frac{P_{\mathrm{O} 2}-\left(\mu Q_{\mathrm{C}} Y_{\mathrm{S}}^{\mathrm{O} 2: \mathrm{BIO}}+R_{\mathrm{m}}+R_{\mathrm{P}}\right)}{4 \pi r \kappa_{\mathrm{O} 2}}$

Oxygenic photosynthesis, $P_{\mathrm{O} 2}$, always acts to increase intracellular oxygen concentration along with invasion from the environment, if the external concentration is higher. In contrast, there are numerous strategies to reduce intracellular oxygen levels and protect nitrogenase, as mentioned in the introduction: living in a low-oxygen environment, reducing $\left[\mathrm{O}_{2}\right]$; increasing the efficiency of respiratory oxygen consumption, $Y_{\mathrm{S}}^{\mathrm{O} 2 \mathrm{BIO}}$; and creating thick membranes or mucus layers to reduce the effective diffusivity of oxygen, $\kappa_{\mathrm{O} 2}$ into the cell. As carbon quota, $Q_{\mathrm{C}}$, increases with cell volume $\left(r^{3}\right)$, increasing cell radius will increase $R_{\mathrm{S}}$ and reduce $\left[\mathrm{O}_{2}\right]_{\mathrm{C}}$, as will increasing growth rate $\mu$ also increase the respiratory oxygen demand. A high maintenance respiration or deliberate respiratory protection, $R_{\mathrm{P}}$, consumes oxygen. The investment in respiratory protection to reduce the intracellular oxygen concentration to very low levels can be estimated by setting
$\left[\mathrm{O}_{2}\right]_{\mathrm{C}}=0$ in Equation (4) and re-arranging:

$R_{\mathrm{P}}=4 \pi r \kappa_{\mathrm{O} 2}\left[\mathrm{O}_{2}\right]+P_{\mathrm{O} 2}-\left(\mu Q_{\mathrm{C}} Y_{\mathrm{S}}^{\mathrm{O} 2 \mathrm{BIO}}+R_{\mathrm{m}}\right)$

The required $R_{\mathrm{P}}$ is the difference between sources due to oxygenesis and diffusive invasion, and the demand from growth and maintenance.

\section{A model of $A$. vinelandii}

$A$. vinelandii employs several of the strategies encapsulated in Equation (4): it employs respiratory protection (see Figure 1). Its radius increases with the environmental oxygen concentration (Post et al., 1982, 1983b; Poole and Hill, 1997). If the respiration rate is proportional to the cell volume, that is, the rate is influenced by $r^{3}$ (which is approximately the case for prokaryotes; Glazier, 2009), and then the cell radius influences the intracellular oxygen concentration in a quadratic manner according to Equation (4). Thus, the influence of the cell radius on oxygen management can be significant. Azotobacter also creates an alginate barrier, as the environmental oxygen concentration increases, and the amount of intracytoplasmic membrane increased with environmental oxygen concentration (Sabra et al., 2000).

Here we extend the simple model of the previous section to develop a more complete representation of a heterotrophic nitrogen fixer (the cell flux model) that we interface with published data on $A$. vinelandii cultures. This constrains the key parameters, and the model, in turn, provides a quantitative interpretation of the cultures. Extending the simple model of Equation (3), we consider carbon, nitrogen, electron and energy flow in a simplified cell. We combine an idealized biochemical model (Rittmann and McCarty, 2001) that guides the evaluation of growth efficiencies such as $Y_{S}^{\mathrm{O} 2: B I O}$, with a diffusive representation of the transport of oxygen and other substrates through the cell membrane and surrounding molecular boundary layer (Staal et al., 2003).

Ultimately, the model has two free parameters: $\varepsilon$, the energetic efficiency of cellular metabolism, and $\varepsilon_{m}$, the efficiency of diffusion of oxygen through the cell membrane. We constrain these parameters using the laboratory data for Azotobacter illustrated in Figure 1, and use the model to infer the cost of nitrogen fixation and the relative effect of different protection mechanisms. Although we focus on Azotobacter, for which systematic data are available, the model is potentially applicable to a broad range of nitrogen-fixing microbes, and we discuss the broader implications in later sections.

The model, depicted schematically in Figure 2, conserves mass, energy (when $R_{\mathrm{P}}=0$ ) and electron flow at the individual scale and in the simulated reactor vessel, and assumes that cultures are in steady state. The key rate Equations (6), (7) and (10) (Table 1) describe the cellular-scale conservation of carbohydrate and oxygen, as well as conservation of carbohydrate in the reactor vessel. 
For a steady state, conservation of carbohydrate at the cellular scale (Equation (6)) balances uptake of the carbohydrate $(\mathrm{CH})$ substrate, $V_{\mathrm{CH}}$, against synthesis into 'biomass' at dilution rate $D\left(\mathrm{~s}^{-1}\right)$, respiration to support that synthesis (the second term in the equation), maintenance respiration $m Q_{\mathrm{C}}$ and additional respiration associated with respiratory protection $R_{P} / Y_{\mathrm{N}-\mathrm{S}}^{\mathrm{O} 2 \mathrm{CH}}$ (all mol C per cell per s).

An expression for the specific carbohydrate uptake rate, $C_{\mathrm{S}}$ (mol $\mathrm{C}$ in carbohydrate $\mathrm{s}^{-1} / \mathrm{mol} \mathrm{C}$ in biomass $)=V_{\mathrm{CH}} / Q_{\mathrm{C}}$, can be found by rearrangement

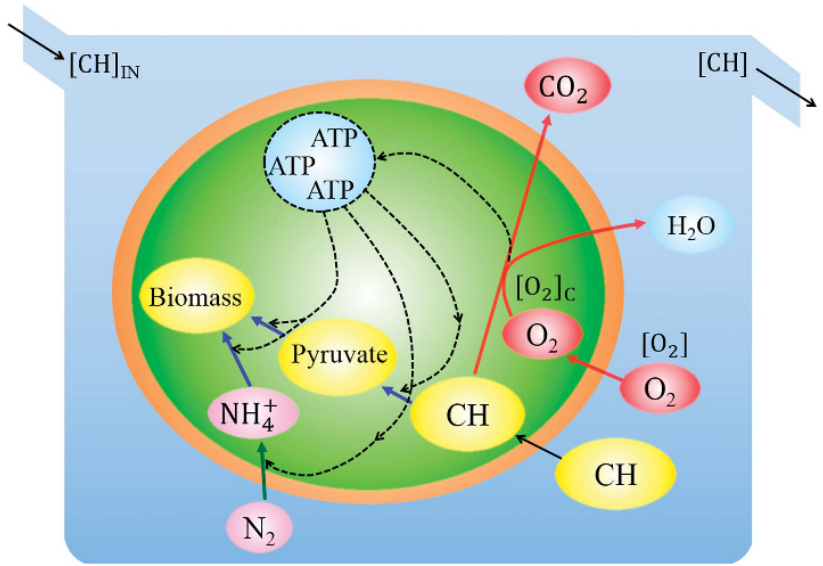

Figure 2 Schematic depiction of the cell flux model in continuous culture. $[\mathrm{CH}]_{\mathrm{IN}}$ is the incoming carbohydrate concentration. $[\mathrm{CH}]$ and $\left[\mathrm{O}_{2}\right]$ are the concentrations of carbohydrate and oxygen in the medium. $\left[\mathrm{O}_{2}\right]_{\mathrm{C}}$ represents the intracellular oxygen concentration. Red arrows represent the energy production pathways and blue arrows represent the biomass synthesis pathways. The green arrow represents nitrogen fixation. The black dashed lines represent energy flow. Orange shading indicates the cell membrane layers. See main text for details. of Equation (6):

$C_{\mathrm{S}}=\frac{Y_{\mathrm{S}}^{\mathrm{CH}}{ }^{\mathrm{BIO}} D}{P_{\mathrm{V}}}+m+\frac{R_{\mathrm{P}}}{Q_{\mathrm{C}} Y_{\mathrm{N}-\mathrm{S}}^{\mathrm{O} 2: \mathrm{CH}}}$

Here $Y_{\mathrm{S}}^{\mathrm{CH}} \mathrm{BIO}$ is the cellular rate of $\mathrm{CH}$ consumption required to supply the balanced electron, carbon and energy for biomass synthesis including nitrogen fixation. $Q_{\mathrm{C}}$ is the cellular quota of carbon (mol C per cell), which is determined as a function of cell volume $V$ (Bratbak and Dundas, 1984); see Supplementary Material S3 for the calculation of $V$. $Y_{\mathrm{N}-\mathrm{S}}^{\mathrm{O} 2 \mathrm{CH}}$ is the ratio in which oxygen is consumed relative to carbohydrate for non-synthesis-related respiration (that is, maintenance and respiratory protection). We evaluate $Y_{\mathrm{S}}^{\mathrm{CH}: \mathrm{BIO}}$ and $Y_{\mathrm{N}-\mathrm{S}}^{\mathrm{O} 2 \mathrm{CH}}$ using the method described by Rittmann and McCarty (2001), balancing mass, electron and energy flow at the individual scale (outlined in Supplementary Material S1). The simple model for $C_{\mathrm{S}}$ in Equation (11) suggests a linear relationship with dilution rate (average growth rate), $D$, and additional costs due to minimal maintenance and respiratory protection. If the latter is neglected $\left(R_{\mathrm{P}}=0\right)$ then Equation (11) represents the classical Pirt model (Pirt, 1982), where $Y_{\mathrm{S}}^{\mathrm{CH}} \mathrm{BIO}$ is constrained by exact energy balance. In this study, however, we assume that the maintenance rate $m$ is negligible, as it is typically small relative to respiratory protection in most instances explored here. We note that $Y_{\mathrm{S}}^{\mathrm{CH}} \mathrm{BIO}$ is a function of the energy transfer efficiency, $\varepsilon$, which characterizes unresolved details of metabolic adaptations (see Results and Discussion, and Supplementary Material S1) and, as such, is a tunable parameter of this model.

The vitality ratio, $P_{\mathrm{V}}$, represents the fraction of active cells in the culture. Under unfavorable conditions, such as nutrient depletion, cells can survive in dormancy with low metabolic rate

Table 1 Fundamental relationships of the cell flux model

Cellular conservation of carbon (mol C cell ${ }^{-1} \mathrm{~s}^{-1}$ )

$\frac{\mathrm{d} Q_{\mathrm{CH}}}{\mathrm{d} t}=V_{\mathrm{CH}}-\frac{D Q_{\mathrm{C}} Y_{\mathrm{S}}^{\mathrm{CH}: \mathrm{BIO}}}{P_{\mathrm{V}}}-m Q_{\mathrm{C}}-\frac{R_{\mathrm{P}}}{Y_{\mathrm{N}-\mathrm{S}}^{\mathrm{O} 2 \mathrm{CH}}}$

Cellular conservation of oxygen $\left(\mathrm{mol} \mathrm{O} \mathrm{Cell}^{-1} \mathrm{~s}^{-1}\right)$

$\frac{\mathrm{d} Q_{\mathrm{O} 2}}{\mathrm{~d} t}=V_{\mathrm{O} 2}-\frac{D Q_{\mathrm{C}} Y_{\mathrm{S}}^{\mathrm{O} 2 \mathrm{BIO}}}{P_{\mathrm{V}}}-m Q_{\mathrm{C}} Y_{\mathrm{N}-\mathrm{S}}^{\mathrm{O} 2: \mathrm{CH}}-R_{\mathrm{P}}$

Cellular oxygen uptake $\left(\mathrm{mol} \mathrm{O}_{2}\right.$ cell $\left.^{-1} \mathrm{~s}^{-1}\right)$

$V_{\mathrm{O} 2}=4 \pi r \kappa_{\mathrm{O} 2}\left(\left[\mathrm{O}_{2}\right]-\left[\mathrm{O}_{2}\right]_{\mathrm{C}}\right)$

Effective diffusivity of oxygen $\left(\mathrm{m}^{2} \mathrm{~s}^{-1}\right)$

$\kappa_{\mathrm{O} 2}=\kappa_{\mathrm{O} 2}^{0} \frac{L_{\mathrm{g}}+r}{L_{\mathrm{g}} / \varepsilon_{\mathrm{m}}+r}$

Conservation of carbon in the reactor $\left(\mathrm{mol} \mathrm{C} \mathrm{m} \mathrm{m}^{-3} \mathrm{~s}^{-1}\right)$

$$
\frac{\mathrm{d}[\mathrm{CH}]}{\mathrm{d} t}=D\left([\mathrm{CH}]_{\mathrm{IN}}-[\mathrm{CH}]\right)-V_{\mathrm{CH}} X P_{\mathrm{V}}
$$

Supplementary Material S5 provides the definition of each parameter. 
(Lennon and Jones, 2011). In continuous culture, there are also dormant or non-vital cells (Postgate, 1973), possibly because of nutrient limitation, and the division rate reflects the average from growing and non-growing cells. The vitality ratio has a significant impact on the growth efficiency as the respiration rate of the non-vital cells is observed to be low (Postgate, 1973). Here we parameterize the fraction of non-vital cells as a function of growth rate based on empirical data of Postgate (1973) for cultures of Klebsiella aerogenes:

$P_{\mathrm{V}}=0.18547 \ln (D)+2.75176$

At present, there are no explicit data on the viability rate of Azotobacter, but incorporating this effect as calibrated for Klebsiella significantly improves the simulation. Specifically, this mechanism reduces the effective yield of the simulation with the dilution rate (that is, increases the slopes of the $C_{\mathrm{S}}$ versus $D$ curves).

Respiratory protection appears as an additional 'maintenance' term in Equation (11), consistent with that observed as the oxygen stress increases in A. vinelandii (increasing the total carbohydrate consumption with oxygen in data on Figure 1a). Higher environmental oxygen concentrations increase the invasion rate, requiring more vigorous respiratory protection and reducing the overall growth efficiency. In order to fix nitrogen, the cell must keep the intracellular oxygen concentration very low (that is, $\left[\mathrm{O}_{2}\right]_{\mathrm{C}} \approx 0$ ) at all rates of growth (dilution). Thus, we can constrain $R_{\mathrm{P}}$ by estimating the rate of oxygen invasion into the cell using Equation (13), derived from Equations (7) and (8) from Table 1 under the steady-state assumption.

$$
\frac{R_{\mathrm{P}}}{Q_{\mathrm{C}}}=\frac{4 \pi r \kappa_{\mathrm{O} 2}\left[\mathrm{O}_{2}\right]}{Q_{\mathrm{C}}}-\frac{D Y_{\mathrm{S}}^{\mathrm{O} 2: \mathrm{BIO}}}{P_{\mathrm{V}}}-m Y_{\mathrm{N}-\mathrm{S}}^{\mathrm{O} 2: \mathrm{CH}}
$$

Here $Y_{\mathrm{S}}^{\mathrm{O} 2 \mathrm{BIO}}$ represents moles of oxygen gas consumed per mole of carbon biomass production for synthesis. Although energy balance can provide some constraint, the realized efficiency of energy transfer depends upon unresolved details of the specific metabolic pathways utilized by the organism and is encapsulated by the energy efficiency parameter, $\varepsilon$ (see Supplementary Material S1).

The diffusive transfer of oxygen from the ambient environment into the cell is described by Equations (8) and (9), following Staal et al. (2003), where the effective diffusivity, $\kappa_{\mathrm{O} 2}$, depends on the diffusivity in water, the cytoplasmic radius, $r$, and the thickness and relative diffusivity of the cell membrane layers ( $L_{\mathrm{g}}$ and $\left.\varepsilon_{\mathrm{m}}\right)$. We impose a positive correlation between the cell radius of Azotobacter and the ambient oxygen concentration based on the empirical data of Post et al. (1982). Here we assume a fixed ratio between the cell membrane thickness and cell radius in order to express the effect of increasing intracytoplasmic-membrane vesicles with the cell radius (Post et al., 1982). As the diffusivity of oxygen in water is well known, we are left with a second control parameter, $\varepsilon_{\mathrm{m}}$. When the invasion of oxygen exceeds the minimum energy demand, the model invokes respiratory protection sufficient to consume all the excess oxygen flux.

Substituting for $R_{\mathrm{P}}$ in Equation (11) with Equation (13) provides a quantitative, mechanistic model for the growth efficiency of nitrogen-fixing Azotobacter that incorporates both direct and indirect costs. Using conservation of carbohydrate in the reactor vessel, Equation (10) in Table 1, and assuming that at the steady state the carbohydrate is drawn down to a low, subsistence concentration (that is, $[\mathrm{CH}]<<$ $[\mathrm{CH}]_{\mathrm{IN}}$ ), we find an expression for the standing concentration of protein in the reactor:

$[\mathrm{PR}]=\frac{D[\mathrm{CH}]_{\mathrm{IN}}}{C_{\mathrm{S}} P_{\mathrm{V}}} Y_{\mathrm{PR}: \mathrm{BIO}}$

where $Y_{\mathrm{PR}: \mathrm{BIO}}$ is the ratio of carbon in protein to carbon in total biomass. We have used 1:1.32 for this ratio based on the laboratory study of Bühler et al. (1987a).

Considerations of mass, electron and energy balance at the individual and reactor scales, along with an estimate of the rate of invasion of oxygen through the cell wall, allowed us to fully describe the system and predict the specific carbohydrate consumption rate, $C_{\mathrm{S}}$ and concentration of protein in the reactor [PR].

\section{Results and discussion}

Direct and indirect costs of nitrogen fixation

The model described above was brought into consistency with the data of Kuhla and Oelze (1988b; data points in Figure 1) by tuning the two control parameters (that is, $\varepsilon_{\mathrm{m}}=7.9 \times 10^{-4}$ and $\varepsilon=0.22$ ) and approximating the energetics of one sucrose molecule as that of two glucose molecules. The simulations qualitatively and quantitatively capture the key features of the laboratory cultures. It identifies the transition between energy-limited and oxygencontrolled regimes in the experiment, confirms that Azotobacter is using several strategies to manage oxygen, quantifies their relative contributions and quantifies the allocation of carbon resources, showing that indirect cost of oxygen management far exceeds the direct cost of nitrogen fixation.

Transition between energy limitation and oxygen management regimes. The solid curves in Figure 1 depict the optimized model solutions for the carbohydrate consumption rate and protein concentration against dilution rate for different oxygen concentrations along with laboratory data in Kuhla and Oelze (1988b). In most cases, the diffusive oxygen supply exceeds the demand for synthesis and the respiratory protection is present, increasing specific sucrose consumption at all dilution rates. However, at higher dilution rates and low ambient oxygen 
concentrations $\left(\left[\mathrm{O}_{2}\right]=12 \mu \mathrm{M}\right)$, respiratory protection is no longer necessary. There growth is oxygenlimited (see equation (3)), and the minimum respiration limit is appropriate. This leads to a sharp transition in the appropriate curves on Figure 1 particularly so for the protein standing stock (Figure 1b); it represents the transition between energy-limited and oxygen management regimes. The model captures and explains this transition.

Multiple oxygen protection strategies. The simulations capture the trend of increasing the carbohydrate consumption rate both with dilution rate and oxygen concentration (Figure 1a, solid lines). When oxygen management is not a major control, for example, the minimum respiration case at $\left[\mathrm{O}_{2}\right]=12 \mu \mathrm{M}$, the increase in the carbohydrate consumption rate with dilution rate is mainly caused by increasing biomass production, nitrogen fixation and balanced respiration. At higher oxygen concentrations, there is an overall increase in carbohydrate consumption because of respiratory protection (that is, appears as a 'maintenance' effect). High dilution rates also increase carbohydrate consumption because of the increased proportion of viable cells, which need respiratory protection for fixing nitrogen, whereas non-viable cells do not.

Figure 3 shows data and model solutions for $C_{\mathrm{S}}$ as a function of oxygen concentration at a fixed dilution rate. The dotted black line indicates the required specific sucrose consumption rate if the cells respond only by respiratory protection to increasing ambient oxygen concentrations. As Oelze (2000) pointed out, this linear response is inconsistent with the data (Figure 3, circles) and demands additional mechanisms. This nonlinearity is captured by the model if the specific invasion rate of oxygen is reduced by an increase in cell radius $\left(r+L_{\mathrm{g}}\right)$ or a

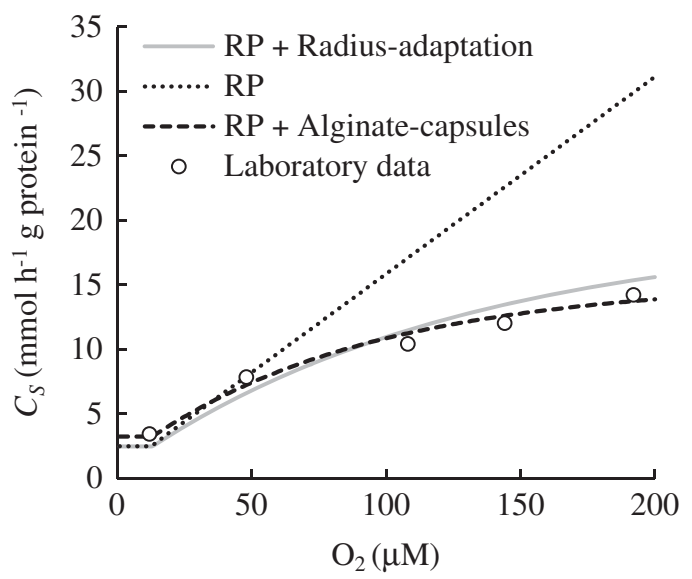

Figure 3 Simulated specific carbohydrate consumption rate as a function of oxygen concentrations for different scenarios: gray solid line, respiratory protection (RP) and radius adaptation. Black dotted line, RP only. Black dashed line, RP and alginate layer formation. Open circles are linearly interpolated values from Kuhla and Oelze (1988b). reduction in the effective diffusivity of oxygen invasion $\left(\kappa_{\mathrm{O}_{2}}\right)$ under higher oxygen concentrations, either by thickening the cell membrane or developing an alginate capsule at higher oxygen concentrations (as observed by Post et al., 1982; Sabra et al., 2000). A relatively minor change in effective cell diameter is sufficient. In the solid grey line of Figure 3 an increase in cell diameter of a factor of $1.4(1.76-2.41 \mu \mathrm{m})$ as oxygen concentration increased from 12 to $192 \mu \mathrm{M}$ brought the model into consistency with the observed data. This is consistent with the increase in size by a factor of 1.6 observed by Post et al. (1982) over a similar range of oxygen concentration in the lab.

Azotobacter can also produce an alginate capsule, which decreases the diffusivity on the cell boundary layer (Sabra et al., 2000), although this phenomenon is not always reported in the laboratory studies. We represent the development of an alginate capsule by altering the effective diffusivity, and imposing a carbohydrate cost for alginate production (dashed black line in Figure 3; for details see Supplementary Material S2). Although sucrose expenditure is increased in order to achieve larger cell radius or alginate layer, the model clearly shows these strategies to significantly improve growth efficiency at higher oxygen concentrations, relative to pure respiratory protection (that is, the solid grey and dashed black are significantly lower than the dotted black line in Figure 3).

The model confirms that multiple oxygen protection strategies must be at play in $A$. vinelandii. At higher oxygen concentrations, changes in cell volume and/or alginate production supplement respiratory protection and significantly increase growth efficiency, whereas at lower concentrations, respiratory protection alone is as effective.

Allocation of resources. The qualitative and quantitative fit to the laboratory data suggest that the model is a suitable tool for quantitative interpretation of resource allocation by $A$. vinelandii in different oxygen environments. The analysis, shown in Figure 4, reveals that in low ambient oxygen concentrations the major respiratory cost is synthesis (Figure 4a). In an oxygenated environment, the greatest carbohydrate cost is for respiratory protection (Figure 4b), and the direct costs of nitrogen fixation are quite small (yellow and red portions, Figure $4 b$ ).

We note that the whole-cell energy-transfer efficiency for Azotobacter, $\varepsilon=0.22$, inferred from the model fit is rather low relative to comparable simulations of other organisms growing on ammonium and glucose, where $\varepsilon=0.54$, using data from Heijnen and Roels (1981). Even when oxygen is low and respiratory protection is not in play (Figure 4a), the efficiency of carbohydrate utilization for synthesis remains relatively low. A. vinelandii expresses cytochrome bd, which has high oxygen consumption relative to ATP production (Poole and 
hill, 1997), trading off low energy efficiency against the ability to manage oxygen for nitrogen fixation. There may also be a high cost in protein turnover, as nitrogenase is so sensitive to even low oxygen concentrations.

\section{Broader Context}

Nitrogen fixation and oxygen management

The comprehensive physiological and energetic data sets characterizing $A$. vinelandii have not been obtained for most nitrogen fixers. However, the model indicates that other types of nitrogen fixers may employ similar oxygen management strategies despite their differences in their sizes and physiology (Table 2). The model has two free parameters that were constrained by minimizing model-data differences: $\varepsilon$ reflects the efficiency of energy production and $\varepsilon_{\mathrm{m}}$ encapsulates the permeability of the cell membrane layers to oxygen. Assuming that this low energy-transfer efficiency is common among nitrogen fixers, we can apply the cell flux model to consider the oxygen management strategies of other nitrogen fixers. Table 2 illustrates the variety of strategies and their occurrence among several nitrogen-fixing species: terrestrial and aquatic, heterotrophic and phototrophic. We note that several of these species are phototrophic; therefore, the energetic constraints may be rather different during the day. However, in the dark (when some are fixing nitrogen) the cell flux model as developed for Azotobacter may be informative.

Crocosphaera is a free living, unicellular marine nitrogen fixer with a typical cell radius of $1 \mu \mathrm{m}$ (estimated from Dron et al., 2012). Großkopf and LaRoche (2012) found that $\sim 60 \%$ of respiration by Crocosphaera is non-essential (that is, respiratory protection) at $186 \mu \mathrm{M} \mathrm{O}_{2}$. We applied the cell flux model framework to a simulation of Crocosphaera in the dark (they fix nitrogen at night) with a growth rate of 0.23 per day (Großkopf and LaRoche, 2012)
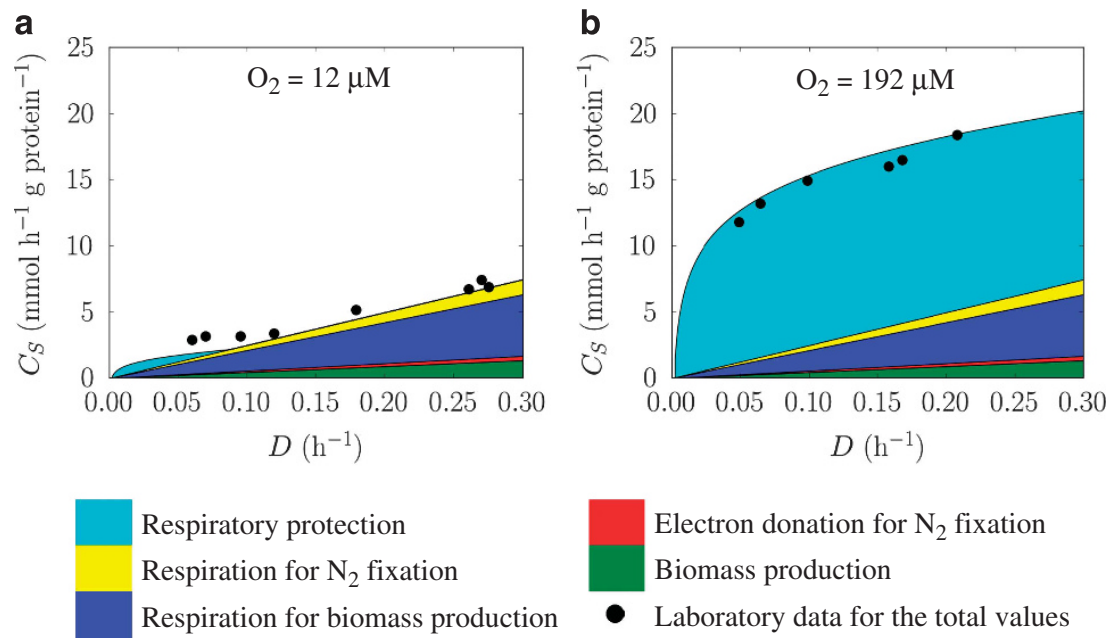

Figure 4 Allocation of carbohydrate resource (as measured by the contribution to specific carbohydrate consumption rate) at (a) $12 \mu \mathrm{M}$ $\mathrm{O}_{2}$ and (b) $192 \mu \mathrm{M} \mathrm{O}_{2}$. Solid circles indicate data from Kuhla and Oelze, 1988b.

Table 2 The list of oxygen management strategies employed by each species

\begin{tabular}{|c|c|c|c|}
\hline Strategy & Size change & Extracellular polymeric substance & Respiratory protection \\
\hline Azotobacter & Yes $^{\mathrm{a}}$ & Alginate $^{\mathrm{b}}$ & Yes $^{\mathrm{c}}$ \\
\hline Anabaena and Nostoc & Yes: heterocysts ${ }^{\mathrm{d}}$ & Highly likely: polysaccharide layer ${ }^{\mathrm{e}}$ & - \\
\hline Crocosphaera & - & Possible: EPS ${ }^{\mathrm{f}}$ & Possible ${ }^{g}$ \\
\hline Trichodesmium & Possible: colony ${ }^{\mathrm{h}}$ & Possible: envelope-related genes ${ }^{\mathrm{i}}$ & Possible ${ }^{j}$ \\
\hline
\end{tabular}

References:

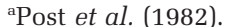

'Sabra et al. (2000).

'Pool and Hill (1997).

${ }^{\mathrm{d}}$ Kumar et al. (2010).

eMaldener and Muro-Pastor (2010).

fDron et al. (2012).

${ }^{\mathrm{g}} \mathrm{Großk}$ kopf and LaRoche (2012).

${ }^{\mathrm{h}}$ Capone et al. (1997).

iYang et al. (2007).

'Berman-Frank et al. (2001). 
and $100 \%$ vitality. To balance the books, the model suggests that Crocosphaera must have a very low effective diffusivity for oxygen (that is, a low $\varepsilon_{\mathrm{m}}$ ), $\sim 1 / 57$ th that of the cell membrane layer of A. vinelandii (in the absence of alginate). Such a low $\mathrm{O}_{2}$ permeability could result from either a thickened cell wall or an extracellular polymer layer analogous to alginate in Azotobacter. The latter is consistent with the significant amounts of extracellular polymeric substances observed in association with Crocosphaera (Dron et al., 2012).

Other organisms use specialized heterocyst cells with very thick cell membranes to exclude oxygen. The cell wall of heterocysts of Anabaena has an effective diffusivity of $\sim 1.18 \times 10^{-12} \mathrm{~m}^{2} \mathrm{~s}^{-1}$ for oxygen (estimated from Walsby (1985)). Simulations with the cell flux model assuming this diffusivity, along with a cell radius of $2.89 \mu \mathrm{m}$ (estimated from Walsby (1985)) and 100\% vitality, we find that at typical saturated oxygen concentrations of $225 \mu \mathrm{M} \mathrm{O}_{2}$ (Post et al., 1982), this organism should not require respiratory protection for growth rates above $\sim 0.10$ per day. Its maximum growth rate is $\sim 0.75$ day (Fogg, 1944).

One strategy of $A$. vinelandii is to increase cell size, therefore reducing surface to volume ratio and the specific invasion rate of oxygen. Forming rafts, with strands of cells bundled together, as seen in the aquatic species Trichodesmium and Aphanizomenon, may have the same effect. Under saturated oxygen concentrations $225 \mathrm{\mu M} \mathrm{O}_{2}$ (Post et al., 1982), cell radius of $2.17 \mu \mathrm{m}$ (estimated from Bidle and Falkowski (2004)), growth rate of 0.23 per day (Prufert-Bebout et al., 1993) and 100\% vitality, our model suggests that for an isolated trichome, 97\% of total respiration would be required for respiratory protection. However, if the colony radius triples because of bundling, the central trichomes are shielded from oxygen with an analogy to increasing the radius of individual cells; the surface to volume ratio is reduced such as to increase efficiency with $\sim 75 \%$ of respiration expended on oxygen management. With colony radius six times that of a single cell, no respiratory protection is needed for the central trichomes. Hence, the formation of bundles may provide a significant enhancement of growth efficiency for Trichodesmium and other marine nitrogen fixers.

Finally, we note that recent studies find heterotrophic nitrogen fixers in various ocean environments (reviewed in Zehr et al., 2003; Riemann et al., 2010), although the exact manner of their lifestyle is yet to be determined. Such organisms might be considered marine analogs of Azotobacter. It might seem surprising that such organisms could thrive in the open ocean: given the energetic cost of oxygen management, it is logical that most marine nitrogen fixers would be photoautotrophic or photoheterotrophic. The high cost of oxygen management in the highly aerobic surface ocean, along with the potential paucity of sufficiently rich organic carbon substrates in the dissolved form, makes it hard to envisage heterotrophic nitrogen fixation as a viable strategy for a free-living cell. However, heterotrophic nitrogen fixation can be favored in certain oxygen conditions. With growth rate of 1 per day, our Azotobacter study suggests a sweet spot of $\sim 3 \% \mathrm{O}_{2}$ saturation at which the organisms are neither oxygen-limited nor poisoned. Such conditions may occur in regions of low oxygen near oxygen minimum zones, or on the microscale in organic particles creating viable habitats. In addition, even under much higher oxygen pressure, given sufficient quantities of carbohydrate substrates, aquatic heterotrophic organisms may carry out nitrogen fixation, as observed recently in Pseudomonas stutzeri (Bentzon-Tilia et al., 2015). Alternatively, symbiosis may lead to fruitful sources of high-energy substrates. Although the precise nature and biogeography of heterotrophic marine nitrogen fixers remain elusive at present, we suggest that the cell flux model developed here may prove to be a useful tool for understanding and modeling these organisms.

\section{Conclusions}

To examine the growth efficiency of nitrogen-fixing bacteria, we have developed a 'cell flux model', constrained by mass, redox and energy balance, to simulate $A$. vinelandii in nitrogen-fixing conditions. The model qualitatively and quantitatively captures the trends in specific carbohydrate consumption, respiration and the standing stock of protein as a function of growth rate and ambient oxygen concentration. It indicates that in oxygenated conditions the direct cost of nitrogen fixation has a limited impact on the growth efficiency of Azotobacter, relative to the major investment in respiratory protection. Azotobacter also employs other strategies to protect nitrogenase from oxygen including an increase in cell radius and the production of an alginate capsule, both of which increase efficiency relative to respiratory protection alone. The strategies for oxygen management employed by Azotobacter are common with many nitrogen fixers, aquatic and terrestrial, heterotrophic and autotrophic. The model has sufficient detail to quantitatively capture many aspects of the energetics and lifestyle of Azotobacter and other nitrogen fixers, yet it remains simple, transparent and computationally cheap. We suggest that it can form the basis for a general physiological model with which to simulate and interpret the relative fitness of microbes of a variety of funcationality in biogeochemical and ecological simulations.

\section{Conflict of Interest}

The authors declare no conflict of interest. 


\section{Acknowledgements}

We thank Stephanie Dutkiewicz for helpful discussions, Krishna Mahadevan for pointing us to the model of Rittmann and McCarty (2001), Eric Stansifer for advice on Python and members of Writing and Communication Center at MIT. We are grateful for support of this work from the Japan Student Service Organization, the Gordon and Betty Moore Foundation (GBMF\#3778) and the Simons Foundation (Simons Collaboration on Ocean Processes and Ecology, Award 329108, Follows).

\section{References}

Allman R, Hann AC, Phillips AP, Martin KL, Lloyd D. (1990). Growth of Azotobacter vinelandii with correlation of coulter cell size, flow cytometric parameters, and ultrastructure. Cytometry 11: 822-831.

Bentzon-Tilia M, Severin I, Hansen LH, Riemann L. (2015). Genomics and ecophysiology of heterotrophic nitrogen-fixing bacteria isolated from estuarine surface water. mBio 6: e00929-15.

Berman-Frank I, Lundgren P, Chen Y-B, Küpper H, Kolber Z, Bergman B et al. (2001). Segregation of nitrogen fixation and oxygenic photosynthesis in the marine cyanobacterium Trichodesmium. Science 294: 1534-1537.

Berman-Frank I, Lundgren P, Falkowski P. (2003). Nitrogen fixation and photosynthetic oxygen evolution in cyanobacteria. Res Microbiol 154: 157-164.

Berman-Frank I, Quigg A, Finkel ZV, Irwin AJ, Liti H. (2007). Nitrogen-fixation strategies and $\mathrm{Fe}$ requirements in cyanobacteria. Limnol Oceanogr 52: 2260-2269.

Bidle KD, Falkowski PG. (2004). Cell death in planktonic, photosynthetic microorganisms. Nat Rev Microbiol 2: 643-655.

Bratbak G, Dundas I. (1984). Bacterial dry matter content and biomass estimations. Appl Environ Microbiol 48: $755-757$.

Bühler T, Monter U, Sann R, Kuhla J, Dingier C, Oelze J. (1987a). Control of respiration and growth yield in ammonium-assimilating cultures of Azotobacter vinelandii. Arch Microbiol 148: 242-246.

Bühler T, Sann R, Monter U, Dingier C, Kuhla J, Oelze J. (1987b). Control of dinitrogen fixation in ammoniumassimilating cultures of Azotobacter vinelandii. Arch Microbiol 148: 247-251.

Capone DG, Zehr JP, Paerl HW, Bergman B, Carpenter EJ. (1997). Trichodesmium, a globally significant marine cyanobacterium. Science 276: 1221-1229.

Colón-López MS, Sherman DM, Herman LA. (1997). Transcriptional and translational regulation of nitrogenase in light-dark- and continuous-lightgrown cultures of the unicellular cyanobacterium Cyanothece sp. strain ATCC 51142. J Bacteriol 179: 4319-4327.

Dalton H, Postgate JR. (1969). Effect of oxygen on growth of Azotobacter chroococcum in batch and continuous cultures. J Gen Microbiol 54: 463-473.

Dixon R, Kahn D. (2004). Genetic regulation of biological nitrogen fixation. Nat Rev Microbiol 2: 621-631.

Dron A, Rabouille S, Claquin P, Chang P, Raimbault V, Talec A et al. (2012). Light:dark (12:12 h) quantification of carbohydrate fluxes in Crocosphaera watsonii. Aquat Microb Ecol 68: 43-55.

Dutkiewicz S, Ward BA, Monteiro F, Follows MJ. (2012). Interconnection of nitrogen fixers and iron in the Pacific Ocean: theory and numerical simulations. Global Biogeochem Cycles 26: GB1012.

Fogg GE. (1944). Growth and heterocyst production in Anabaena cylindrica lemm. New Phytol 43: 164-175.

Gallon JR. (1981). The oxygen sensitivity of nitrogenase: a problem for biochemists and micro-organisms. Trends Biochem Sci 6: 19-23.

Glazier DS. (2009). Metabolic level and size scaling of rates of respiration and growth in unicellular organisms. Funct Ecol 23: 963-968.

Goebel NL, Edwards CA, Church MJ, Zehr JP. (2007). Modeled contributions of three types of diazotrophs to nitrogen fixation at Station ALOHA. ISME $J$ 1: 606-619.

Golden JW, Yoon H-S. (2003). Heterocyst development in Anabaena. Curr Opin Microbiol 6: 557-563.

Großkopf T, LaRoche J. (2012). Direct and indirect costs of dinitrogen fixation in Crocosphaera watsonii WH8501 and possible implications for the nitrogen cycle. Front Microbiol 3: 236.

Heijnen JJ, Roels JA. (1981). A macroscopic model describing yield and maintenance relationships in aerobic fermentation processes. Biotechnol Bioeng 23: 739-763.

Krishnamurthy A, Moore JK, Zender CS, Luo C. (2007). Effects of atmospheric inorganic nitrogen deposition on ocean biogeochemistry. J Geophys Res 112: G02019.

Kuhla J, Oelze J. (1988a). Dependence of nitrogenase switch-off upon oxygen stress on the nitrogenase activity in Azotobacter vinelandii. J Bacteriol 170: 5325-5329.

Kuhla J, Oelze J. (1988b). Dependency of growth yield, maintenance and $K_{\mathrm{s}}$-values on the dissolved oxygen concentration in continuous cultures of Azotobacter vinelandii. Arch Microbiol 149: 509-514.

Kumar K, Mella-Herrera RA, Golden JW. (2010). Cyanobacterial heterocysts. Cold Spring Harb Perspect Biol 2: a000315.

LaRoche J, Breitbarth E. (2005). Importance of the diazotrophs as a source of new nitrogen in the ocean. J Sea Res 53: 67-91.

Lennon JT, Jones SE. (2011). Microbial seed banks: the ecological and evolutionary implications of dormancy. Nat Rev Microbiol 9: 119-130.

Maldener I, Muro-Pastor AM. (2010). Cyanobacterial heterocysts. In: Encyclopedia of Life Sciences (ELS). John Wiley \& Sons Ltd: Chichester.

Misra HS. (1999). Oxygen implication in the diazotrophic growth of Plectonema boryanum in dark-light cycles. Plant Sci 143: 135-142.

Monteiro FM, Follows MJ, Dutkiewicz S. (2010). Distribution of diverse nitrogen fixers in the global ocean. Global Biogeochem Cycles 24: GB3017.

Nagai S, Aiba S. (1972). Reassessment of maintenance and energy uncoupling in the growth of Azotobacter vinelandii. J Gen Microbiol 73: 531-538.

Neilson A, Rippka R, Kunisawa R. (1971). Heterocyst formation and nitrogenase synthesis in Anabaena sp. Arch Mikrobiol 76: 139-150.

Oelze J. (2000). Respiratory protection of nitrogenase in Azotobacter species: is a widely held hypothesis 
unequivocally supported by experimental evidence? FEMS Microbiol Rev 24: 321-333.

Pirt SJ. (1982). Maintenance energy: a general model for energy-limited and energy-sufficient growth. Arch Microbiol 133: 300-302.

Poole RK, Hill S. (1997). Respiratory protection of nitrogenase activity in Azotobacter vinelandii-Roles of the terminal oxidases. Biosci Rep 17: 303-317.

Post E, Golecki JR, Oelze J. (1982). Morphological and ultrastructural variations in Azotobacter vinelandii growing in oxygen-controlled continuous culture. Arch Microbiol 133: 75-82.

Post E, Kleiner D, Oelze J. (1983a). Whole cell respiration and nitrogenase activities in Azotobacter vinelandii growing oxygen controlled continuous culture. Arch Microbiol 134: 68-72.

Post E, Vakalopoulou E, Oelze J. (1983b). On the relationship of intracytoplasmic to cytoplasmic membranes in nitrogen-fixing Azotobacter vinelandii. Arch Microbiol 134: 265-269.

Postgate JR. (1973). The viability of very slow-growing populations: a model for the natural ecosystem. Bull Ecol Res Comm 17: 287-292.

Prufert-Bebout L, Paerl HW, Lassen C. (1993). Growth, nitrogen fixation, and spectral attenuation in cultivated Trichodesmium species. Appl Environ Microbiol 59: 1367-1375.

Riemann L, Farnelid H, Steward GF. (2010). Nitrogenase genes in non-cyanobacterial plankton: prevalence, diversity and regulation in marine waters. Aquat Microb Ecol 61: 235-247.

Rittmann BE, McCarty PL. (2001). Stoichiometry and bacterial energetics. In: Environmental Biotechnology: Principles and Applications. McGraw-Hill: New York, NY, USA, pp 126-164.

Sabra W, Zeng AP, Lünsdorf H, Deckwer WD. (2000). Effect of oxygen on formation and structure of Azotobacter vinelandii alginate and its role in protecting nitrogenase. Appl Environ Microbiol 66: 4037-4044.

Saito MA, Bertrand EM, Dutkiewicz S, Bulygin VV, Moran DM, Monteiro FM et al. (2011). Iron conservation by reduction of metalloenzyme inventories in the marine diazotroph Crocosphaera watsonii. Proc Natl Acad Sci USA 108: 2184-2189.

Sohm JA, Webb EA, Capone DG. (2011). Emerging patterns of marine nitrogen fixation. Nat Rev Microbiol 9: 499-508.

Staal M, Meysman FJR, Stal LJ. (2003). Temperature excludes $\mathrm{N}_{2}$-fixing heterocystous cyanobacteria in the tropical oceans. Nature 425: 504-507.

Stukel MR, Coles VJ, Brooks MT, Hood RR. (2014). Top-down, bottom-up and physical controls on diatom-diazotroph assemblage growth in the Amazon River plume. Biogeosciences 11: 3259-3278.

Tucker DL, Hirsh K, Li H, Boardman B, Sherman LA. (2001). The manganese stabilizing protein (MSP) and the control of $\mathrm{O}_{2}$ evolution in the unicellular, diazotrophic cyanobacterium, Cyanothece sp. ATCC 51142. Biochim Biophys Acta 1504: 409-422.

Walsby AE. (1985). The permeability of heterocysts to the gases nitrogen and oxygen. Proc $R$ Soc B Biol Sci 226: $345-366$.

Wolk CP. (1996). Heterocyst formation. Annu Rev Genet 30: $59-78$.

Yang Y, Qin S, Zhao F, Chi X, Zhang X (2007). Comparison of envelope-related genes in unicellular and filamentous cyanobacteria. Comp Funct Genomics 2007: 25751.

Zehr JP, Jenkins BD, Short SM, Steward GF. (2003). Nitrogenase gene diversity and microbial community structure: a cross-system comparison. Environ Microbiol 5: 539-554.

(i) () () This work is licensed under a Creative Commons Attribution-NonCommercial-

NoDerivs 4.0 International License. The images or other third party material in this article are included in the article's Creative Commons license, unless indicated otherwise in the credit line; if the material is not included under the Creative Commons license, users will need to obtain permission from the license holder to reproduce the material. To view a copy of this license, visit http://creativecommons.org/ licenses/by-nc-nd/4.0/

Supplementary Information accompanies this paper on The ISME Journal website (http://www.nature.com/ismej) 